\title{
Increased blood pressure in adult offspring of families with Balkan Endemic Nephropathy: a prospective study
} Plamen S Dimitrov ${ }^{1}$, Valeri A Simeonov ${ }^{2}$, Svetlana D Tsolova ${ }^{1}$, Angel G Bonev ${ }^{2}$, Rossitza B Georgieva ${ }^{1}$ and Wilfried J Karmaus*3

\author{
Address: ${ }^{1}$ National Center of Public Health Protection, 15 "Acad. Ivan Geshov" Street, Sofia, Bulgaria, ${ }^{2}$ Vratza District Hospital, "2 June" Street, \\ Vratza, Bulgaria and ${ }^{3}$ Department of Epidemiology and Biostatistics, University of South Carolina, 800 Sumter Street, Columbia, South Carolina, \\ USA \\ Email: Plamen S Dimitrov - p.dimitrov@ncphp.government.bg; Valeri A Simeonov - p.dimitrov@ncphp.government.bg; \\ Svetlana D Tsolova - sv.tzolova@ncphp.government.bg; Angel G Bonev - p.dimitrov@ncphp.government.bg; \\ Rossitza B Georgieva - r.georgieva@ncphp.government.bg; Wilfried J Karmaus* - karmaus@sc.edu \\ * Corresponding author
}

Published: 23 August 2006

BMC Nephrology 2006, 7:12 doi:10.1/86/147/-2369-7-12
Received: 16 February 2006

Accepted: 23 August 2006

This article is available from: http://www.biomedcentral.com/I47/-2369/7//2

(c) 2006 Dimitrov et al; licensee BioMed Central Ltd.

This is an Open Access article distributed under the terms of the Creative Commons Attribution License (http://creativecommons.org/licenses/by/2.0), which permits unrestricted use, distribution, and reproduction in any medium, provided the original work is properly cited.

\begin{abstract}
Background: Previous studies have linked smaller kidney dimensions to increased blood pressure. However, patients with Balkan Endemic Nephropathy (BEN), whose kidneys shrink during the course of the disease, do not manifest increased blood pressure. The authors evaluated the relationship between kidney cortex width, kidney length, and blood pressure in the offspring of BEN patients and controls.
\end{abstract}

Methods: 102 offspring of BEN patients and 99 control offspring of non-BEN hospital patients in the Vratza District, Bulgaria, were enrolled in a prospective study and examined twice (2003/04 and 2004/05). Kidney dimensions were determined using ultrasound, blood pressure was measured, and medical information was collected. The parental disease of BEN was categorized into three groups: mother, father, or both parents. Repeated measurements were analyzed with mixed regression models.

Results: In all participants, a decrease in minimal kidney cortex width of $\mathrm{I} \mathrm{mm}$ was related to an increase in systolic blood pressure of $1.4 \mathrm{~mm} \mathrm{Hg}(p=0.005)$. There was no association between kidney length and blood pressure. A maternal history of BEN was associated with an increase in systolic blood pressure of $6.7 \mathrm{~mm} \mathrm{Hg}(p=0.03)$; paternal $B E N,+3.2 \mathrm{~mm} \mathrm{Hg}(p=0.35)$; or both parents affected, $+9.9 \mathrm{~mm} \mathrm{Hg}(p=0.002)$. There was a similar relation of kidney cortex width and parental history of BEN with pulse pressure; however, no association with diastolic blood pressure was found.

Conclusion: In BEN and control offspring, a smaller kidney cortex width predisposed to higher blood pressure. Unexpectedly, a maternal history of BEN was associated with average increased systolic blood pressure in offspring. 


\section{Background}

There is a large body of evidence that patients with Balkan Endemic Nephropathy (BEN), in contrast to other chronic kidney diseases $[1,2]$, do not manifest increased blood pressure [3-9]. However, little is known about the development of blood pressure in BEN patients, in particular, whether increased blood pressure occurs in preclinical stages. BEN was first characterized in the Vratza District, Bulgaria in 1956 [10]. Later, similar nephropathies were described in Yugoslavia in $1957[3,10]$ and in Romania in 1961 [11]. As a result, in 1964, the disease was recognized as a new nosological entity and was named Balkan Endemic Nephropathy. BEN is a tubulo-interstitial kidney disease that progresses slowly for many years. The final disease stage is characterized by renal failure and shrinkage of both kidneys to 3-4 cm in length [12]. Recent studies have shown that the offspring of BEN patients have smaller kidney lengths or cortex widths $[13,14]$, which may be a marker of a reduced number of nephrons $[15,16]$. Mackenzie et al. advanced the hypothesis that the total nephron number is a factor determining susceptibility to increased blood pressure [17]. In addition, there is evidence that the number of nephrons co-determines kidney dimensions [18]. Lastly, Singh et al. and Zumrutdal et al. have shown that decreased kidney dimensions are associated with increased systolic blood pressure $[16,19]$.

We conducted a prospective study in the Vratza District of Bulgaria, a rural area, and measured the kidney cortex width, kidney length, and blood pressure of the offspring of BEN patients and control offspring at two time points, one year apart. We hypothesize the following:

- A smaller kidney cortex width is related to a higher average systolic blood pressure and a higher pulse pressure.

- An offspring with parental history of BEN has a higher average systolic blood pressure and a higher pulse pressure.

\section{Methods \\ Population}

In the period of October, 2003, to April, 2004, we recruited adult offspring (102 study subjects) whose father and/or mother were included in the Vratza Hospital registry of BEN patients in 2001 and who resided in one of three communities (Vratza, Bistretz, or Beli Izvor, Bulgaria). The diagnosis of BEN in the parent generation is based on three groups of criteria: epidemiological, clinical/laboratory, and pathological/anatomical [20]. Regarding epidemiology, the region is known to have a higher prevalence of $\mathrm{BEN}$, thus, the only individual criterion is onset after the age of 20. Clinical and laboratory criteria are a follows: obscure onset, chronic course, no sense of edema, and normochromic type of anemia in more advanced phases. Pathologically, an almost symmetrical macroscopic shrinkage of the two kidneys was required in the parent BEN population. A control group of equal size comprised of adult offspring (99 study subjects) of nonBEN hospitalized patients was enrolled in the study during the same time period. Diagnoses in control parents included diabetes mellitus, cardiovascular disorders, and liver problems. Only three of the 99 parents had kidney disorders (one paternal kidney cancer not related to BEN and two maternal pyelonephritis cases). Subjects of both groups were matched according to gender and ten-year age groups. All participants provided written or verbal consent (witnessed) through a procedure approved by the Institutional Review Board (human-subject research committee) of the National Center of Public Health Protection, Sofia, Bulgaria. The population was enrolled and examined in 2003/04 and investigated again in 2004/05, which provided us with two repeated measurements one year apart.

\section{Interviews}

We conducted face-to-face interviews with all participants either in the hospital, or by visiting them in their home villages. The standardized questionnaire asked for the place of living, type of water supply, diet, smoking and drinking habits, medical symptoms, family history of BEN, family history of other kidney diseases and kidney tumors, and occupational history.

\section{Physical examination}

The physical examination was performed by an experienced physician with board certification in internal diseases and nephrology. It was aimed at assessing the general health status of the study subjects and at revealing symptoms of BEN and/or other internal diseases. Blood pressure was measured according to standards set by the World Health Organization [21]. Participants were in the seated position; three measurements were taken on the right arm at 5 minute intervals. We recorded systolic and diastolic blood pressure and calculated pulse pressure as the difference between these two values.

\section{Determination of the kidney sizes}

Ultrasound investigations of both kidneys took 20-30 minutes. The patient was investigated lying on both the left and right sides. After finding a suitable image, measurements were taken. The longest dimension of the kidney was determined. The thickness of the kidney parenchyma (in the thinnest or minimal part), parenchyma structure, and the relationship of parenchyma and pyelon were measured. Information gathered also included the location, size, and morphology (cysts, stones, and tumors) of the kidneys. The images were saved electronically for future reference. The ultrasonographer (AGB) worked in the Department of Image Diagnostics, 
Vratza District Hospital, and was blinded to the clinical status of the participant (BEN or control offspring).

\section{Blood collection and analysis of lead}

Blood samples were drawn in $\mathrm{K}_{2}$ EDTA vacutainers. Lead in blood was determined by using atomic absorption spectrometry. A Model $4110 \mathrm{ZL}$ atomic absorption spectrometer (Bodenseewerk Perkin-Elmer, Ueberlingen, Germany) with a transverse heated graphite atomizer and longitudinal Zeeman-effect background correction equipped with an AS-72 autosampler, electrodeless discharge lamps System II, software WinLab (Version 1.2) and both "Standard"(Part No B 300-0643) and "Endcapped" (Part No B 300-0644) THGA tubes with integrated platforms was used for direct electrothermal AAS measurements. To measure lead, blood was diluted 10fold with $0.25 \% \mathrm{v} / \mathrm{v}$ Triton $\mathrm{X}-100 ; 10 \mu \mathrm{L}$ of the sample and $25 \mu \mathrm{g}$ of $\left(\mathrm{NH}_{4}\right)_{2} \mathrm{HPO}_{4}$ as a chemical modifier were injected in the THGA, pre-treated with $250 \mu \mathrm{g}$ of zirconium and $20 \mu \mathrm{g}$ iridium. Matrix-matched calibrations were applied [22]. Certified reference materials (Seronorm Trace Elements Whole Blood, Level 1, Cat. No 201505, and Level 2, Cat. No 201605, Sero AS, Norway) were used for internal laboratory control.

\section{Statistical analyses}

Outcome variables were diastolic, systolic blood pressure, and pulse pressure. For descriptive purposes, we defined moderate hypertension as a systolic blood pressure $\geq 150$ $\mathrm{mm} \mathrm{Hg}$ and a diastolic blood pressure $\geq 100 \mathrm{~mm} \mathrm{Hg}$. However to investigate average increases, the explanatory models used the three continuous outcome variables.

To answer the question whether minimal kidney cortex width is related to higher blood pressure, we controlled for potentially confounding factors such as gender, age, history of smoking, diabetes mellitus, parental history of hypertension or of Balkan Endemic Nephropathy, body surface area, and blood lead level. For smoking, we categorized a subject as being a current smoker, ex-smoker, or non-smoker. A parental history of high blood pressure fell into one of three groups: mother, father, or both affected. We asked for presence of diabetes mellitus in the first investigation (2003/04) and for a new occurrence in the second investigation. The body surface area (BSA) was calculated as ([height * weight]/3600) ${ }^{2}$. This variable is used in the model to control for the effect of weight and height on kidney size and on blood pressure. In each investigation (2003/04 and 2004/05) the average kidney cortex width and kidney length of both kidneys were used as predictors.

To test the hypothesis that offspring of BEN parents have increased blood pressure, we grouped parental disease status into three groups: mother, father, or both parents affected. None of the comparison offspring fell into any of these groups (reference). The effect of cortex width and parental BEN status was tested in the same model.

In order to estimate the association of minimal kidney width and parental history of BEN with blood pressure based on repeated measurements, we applied linear mixed models. Measurements of the two investigations are not independent and mixed models allow adjusting for within-participant effects [23]. The mixed model assumes that the random effects and the error vector are normally distributed, which was the case for the blood pressure variables. SAS PROC MIXED was used to perform the regression analysis [24]. We used Akaike information criteria and the likelihood ratio test to examine the significance of serial correlation (in repeated statement) as well as to model random effects, along with a suitable variance-covariance matrix structure.

To compare the agreement between measurements of continuous variables in 2003/04 and 2004/05 we used the intra-class correlation coefficient (ICC). This is the between-subject minus the within-subject variance divided by the sum of the two variances. The ICC quantifies the proportion of total outcome variance that is due to inter-individual variation.

\section{Results}

Of the 201 participants in the first investigations (2003/ 04), 189 participated in the follow-up $(2004 / 05,94 \%)$. Two were deceased, one moved out of the area, two could not be contacted, and 7 decided not to participate further. Of the 12 lost, 9 were offspring of BEN patients. Potential risk factors show similar distributions in each of the two investigations (Table 1). One participant had newly developed diabetes. Comparison offspring were about 1.5 to 2 $\mathrm{cm}$ taller than BEN offspring; however, the latter were on average $1.5 \mathrm{~kg}$ heavier. Blood pressure seems to be higher in BEN offspring: $30.4 \%$ were classified as having moderate hypertension (systolic blood pressure $\geq 140$ and/or diastolic $\geq 90 \mathrm{~mm} \mathrm{Hg}$ ) in the investigation in 2003/04 and $33.3 \%$ in 2004/05 (Table 1). The prevalence of moderate hypertension in our rural sample, with a mean age of 50 years, is only marginally lower than the proportion reported in another study of urban population of the same age in Bulgaria [25]. Also, offspring of BEN patients reported more antihypertensive treatment in the year before the investigation.

Figure 1 shows the agreement between the two systolic blood pressure measurements one year apart. The intraclass correlation coefficient (ICC) of 0.68 (lower 5\% limit: 0.61 ) was good for systolic blood pressure, but lower for diastolic blood pressure $(\mathrm{ICC}=0.49$, lower $5 \%$ limit: 0.39). For the minimal cortex width, the ICC was 0.66 
Table I: Characteristics of the Study Population of the Adult Offspring Study Cohort

\begin{tabular}{|c|c|c|c|c|c|}
\hline & & \multicolumn{2}{|c|}{ Investigation in 2003/04 } & \multicolumn{2}{|c|}{ Investigation in $2004 / 05$} \\
\hline & & $\begin{array}{c}\text { Offspring of BEN } \\
\text { patients, } n=102(\%)\end{array}$ & $\begin{array}{l}\text { Offspring of control } \\
\text { patients, } n=99(\%)\end{array}$ & $\begin{array}{c}\text { Offspring of BEN } \\
\text { patients, } n=93(\%)\end{array}$ & $\begin{array}{l}\text { Offspring of control } \\
\text { patients, } \mathrm{n}=96(\%)\end{array}$ \\
\hline Gender & male & 50.0 & 47.5 & 48.8 & 47.9 \\
\hline \multirow[t]{3}{*}{ Smoking } & $\begin{array}{l}\text { Current } \\
\text { smoker }\end{array}$ & 39.2 & 34.3 & 38.7 & 35.4 \\
\hline & Ex-smoker & 22.6 & 12.1 & 21.5 & 12.5 \\
\hline & Non-smoker & 38.4 & 53.5 & 39.8 & 52.1 \\
\hline Diabetes & Yes & 7.8 & 6.1 & 5.4 & 7.3 \\
\hline \multirow[t]{3}{*}{ Parental history of hypertension } & Mother & 19.6 & 16.2 & 20.4 & 16.7 \\
\hline & Father & 13.7 & 16.2 & 15.1 & 16.7 \\
\hline & Both & 2.9 & 5.1 & 3.2 & 5.2 \\
\hline \multirow[t]{3}{*}{ Parental history of BEN } & Mother & 38.2 & 0 & 38.7 & 0 \\
\hline & Father & 25.2 & 0 & 25.8 & 0 \\
\hline & Both & 36.3 & 0 & 35.5 & 0 \\
\hline Moderate hypertension in the offspr & ing $\xi$ & 30.4 & 19.2 & 32.3 & 22.9 \\
\hline \multicolumn{2}{|c|}{ Antihypertensive medication } & 22.5 & 5.1 & 29.0 & 12.5 \\
\hline & & \multicolumn{4}{|c|}{ Mean (standard deviation) or median and $95 \%$ confidence interval ${ }^{\dagger}$} \\
\hline Age & (years) & $47.3(9.4)$ & $49.6(9.1)$ & $50.4(9.2)$ & $48.8(9.6)$ \\
\hline Systolic blood pressure & $(\mathrm{mm} \mathrm{Hg})$ & $130.7(20.1)$ & $124.9(17.6)$ & 135.| (23.0) & $126.1(19.1)$ \\
\hline Diastolic blood pressure & $(\mathrm{mm} \mathrm{Hg})$ & $80.8(12.2)$ & $78.9(10.5)$ & $83.5(14.0)$ & $80.6(12.5)$ \\
\hline Pulse pressure $\$$ & $(\mathrm{~mm} \mathrm{Hg})$ & $49.3(13.3)$ & $46.2(12.1)$ & $51.5(13.3)$ & $45.5(10.7)$ \\
\hline Weight & $(\mathrm{kg})$ & $75.8(14.8)$ & $73.6(11.6)$ & $73.3(14.2)$ & $71.9(11.1)$ \\
\hline Height & $(\mathrm{cm})$ & $167.7(8.5)$ & $169.4(7.7)$ & $163.8(9.0)$ & $165.3(7.7)$ \\
\hline Body surface area \# & $\left(\mathrm{m}^{2}\right)$ & $1.87(0.22)$ & $1.86(0.2)$ & $\mathrm{I} .82(0.2 \mathrm{I})$ & $1.81(0.2)$ \\
\hline Minimal width of the kidney cortex & $(\mathrm{mm})$ & I5.5 (2.03) & $15.9(1.9)$ & $15.2(2.1)$ & $15.6(1.8)$ \\
\hline Kidney length & $(\mathrm{mm})$ & $116.7(6.8)$ & $119.6(7.0)$ & $117.3(6.8)$ & $119.2(6.8)$ \\
\hline Lead in whole blood & $\begin{array}{l}(\mu \mathrm{g} / \mathrm{L}, \text { median } \\
\text { and } 95 \% \mathrm{Cl}) ¥\end{array}$ & $93.8(50-205)$ & $87.6(42-225)$ & $87.7(4 \mid-210)$ & $84(39-203)$ \\
\hline
\end{tabular}

† A median was used if the variable was not normally distributed.

$\$$ Difference of systolic minus diastolic blood pressure

$¥ 95 \% \mathrm{Cl}-95 \%$ confidence interval

\# Body surface area $=([$ height $*$ weight $] / 3600) 2$

$\xi$ Systolic blood pressure $\geq 140$ and/or diastolic $\geq 90 \mathrm{~mm} \mathrm{Hg}$.

(lower 5\% limit: 0.58 ) and 0.92 for kidney length (lower limit: 0.89). Blood lead concentration also showed good agreement (ICC $=0.65$, lower limit: 0.57 ).

The study population consists of 201 subjects that provided 388 observations (two measurements for most participants, one year apart). When analyzing blood pressure differences while controlling for confounders, cortex width and parental BEN status had significant effects on systolic and pulse pressure, but not on diastolic blood pressure. A decrease in the minimal kidney cortex of $1 \mathrm{~mm}$ was linearly related to an increase in systolic blood pressure of $1.4 \mathrm{~mm} \mathrm{Hg}(\mathrm{p}=0.005)$ and an increase of pulse pressure of $1.1 \mathrm{~mm} \mathrm{Hg}(\mathrm{p}=0.002)$.

Figure 2 shows the scatter plot of minimal cortex width and pulse pressure using a cubic regression with 95\% confidence limits. A cubic regression fitted the observations best when no other predictors were taken into consideration. Within the boundaries of our measurements of the cortex width there was no decrease in blood pressure once the minimal kidney cortex width was $16 \mathrm{~mm}$ or larger. Blood pressure started to increase when the width was smaller than $16 \mathrm{~mm}$.

A maternal history of BEN was associated with an increased systolic blood pressure in offspring of $6.7 \mathrm{~mm}$ Hg ( $\mathrm{p}=0.03)$, and when both parents had BEN, an increased systolic blood pressure of $9.9 \mathrm{~mm} \mathrm{Hg}(\mathrm{p}=$ 0.002). There was no statistically significant effect of a paternal history of BEN.

To investigate whether the use of antihypertensive medication had distorted our findings, we repeated the model excluding those observations with antihypertensive drug use. This reduced the number of repeated observation from 388 to 322 (176 subjects), but did not change our findings.

\section{Discussion}

Our findings show that a decrease of the minimal kidney cortex width of $1 \mathrm{~mm}$ was related to an increase in systolic 


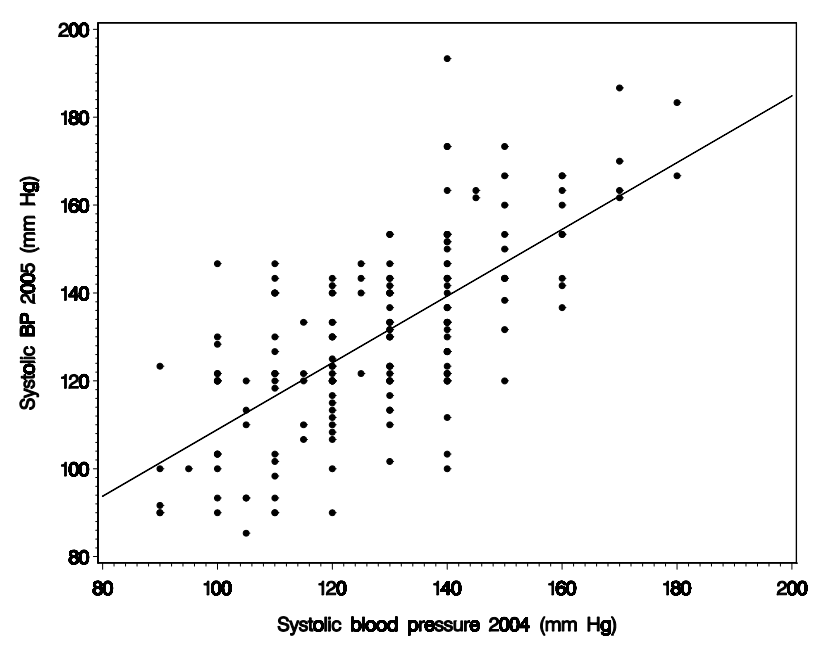

Figure I

Comparisons of systolic blood pressure measurements in 2003/04 and 2004/05.

blood pressure of $1.4 \mathrm{~mm} \mathrm{Hg}$. There was no association between kidney length and blood pressure. A maternal history of BEN was associated with a significant increase in systolic blood pressure of $6.7 \mathrm{~mm} \mathrm{Hg}$, paternal BEN with a non-significant increase of $3.2 \mathrm{~mm} \mathrm{Hg}$, and both parents affected, a significant increase of $9.9 \mathrm{~mm} \mathrm{Hg}$. The lack of association of either kidney cortex width or a parental history of BEN with diastolic blood pressure may

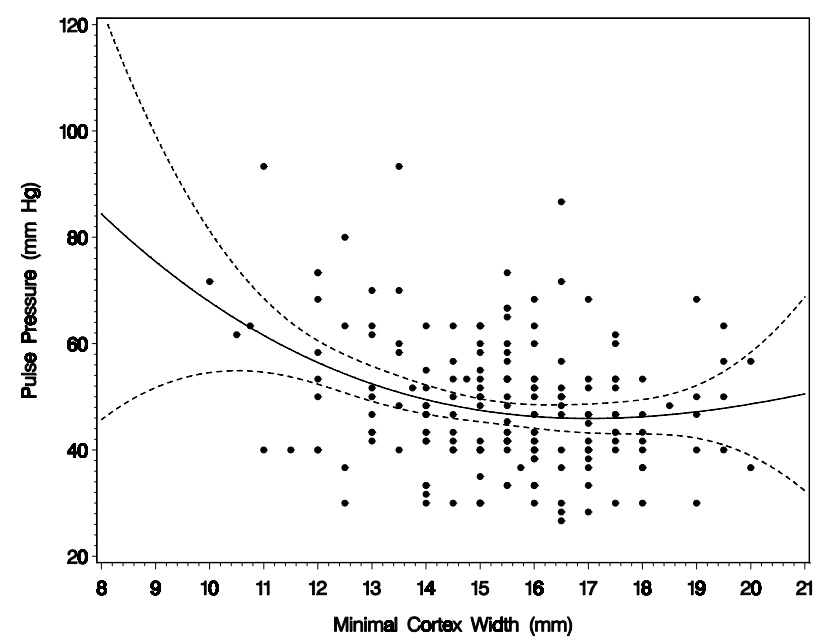

Figure 2

Scatterplot of minimal kidney cortex width with pulse pressure in the 2004/05 investigation (crude association; for adjusted effects, see Table 2). The straight line shows the estimated cubic association, the dotted lines show the $95 \%$ confidence limits. either stem from the larger individual variance of this parameter or may indicate that there is no such link.

In a study with healthy volunteers in England, Raman et al. did not identify a clear pattern between measurements of the right and left kidneys and blood pressure [26]. In another population-based study, Paivansalo et al. found that the kidneys of hypertensive women were slightly larger ( $p<0.08)$ [27]. To the contrary, comparing hypertensive and normotensive Turkish patients, Zumrutdal et al. found that kidney length and volume were significantly smaller in hypertensive patients [19]. Thus, it is not clear whether hypertension affects kidney dimensions or vice versa.

For adult Aboriginals in Australia, Singh et al. found that a $10 \mathrm{~mL}$ decrease in kidney volume was associated with a $0.5 \mathrm{~mm} \mathrm{Hg}$ increase in systolic blood pressure [16]. The study of Singh et al. did not provide information on cortex width; in our study we do not have information on kidney volume. To compare results, we expressed both findings as a percent decrease in kidney dimensions. A $10 \mathrm{~mL}$ decrease in kidney volume in the Australian study represents approximately a 5\% decrease in volume (range: 62 $267 \mathrm{~mL}$ ). In our study of adult Caucasian offspring from Bulgaria, a 5\% decrease in the minimal cortex width $(0.5$ $\mathrm{mm}$, range $10-20 \mathrm{~mm}$ ) is associated with a $0.7 \mathrm{~mm} \mathrm{Hg}$ increase in blood pressure. Thus, both studies found a similar effect of kidney dimensions on blood pressure. Singh et al. also showed a cubic-type association between kidney volume and systolic blood pressure. Similarly, we have demonstrated a cubic regression between minimal kidney cortex width and blood pressure; the threshold we detected in our model, is approximately $16 \mathrm{~mm}$ of cortex width. However, if we control for other variables in mixed regression models, a straight line is also appropriate (Table 2).

Mackenzie et al. posited the hypothesis that the total nephron supply at birth is a factor in determining a susceptibility to increased blood pressure [17]. Given that kidney dimensions correlate with the number of nephrons [18], our finding that minimal cortex width is significantly associated with systolic and pulse pressure supports Mackenzie's hypothesis. In addition, we found that, in offspring, maternal BEN is associated with increased systolic and pulse pressure. In a prior report of this project, we showed that a maternal but not a paternal history of BEN is related to reduced cortex width in their adult offspring [14]. The stronger role of maternal BEN in offspring susceptibilities (cortex width and average blood pressure) and the lack of paternal-related risks may indicate, in our opinion, the importance of feto-maternal interactions during pregnancy. Mothers who later develop $\mathrm{BEN}$ do not yet have the disease during their childbearing 
Table 2: Effect of kidney Measures and Parental History of Balkan Endemic Nephropathy on Blood Pressure in Adult Offspring

\begin{tabular}{|c|c|c|c|c|c|c|c|}
\hline & & \multicolumn{2}{|c|}{ Diastolic blood pressure } & \multicolumn{2}{|c|}{ Systolic blood pressure } & \multicolumn{2}{|c|}{ Pulse pressure } \\
\hline & & $\begin{array}{c}\text { Parameter } \\
\text { estimate } \#(\mathrm{~mm} \\
\mathrm{Hg})\end{array}$ & $\mathrm{p}$-value & $\begin{array}{c}\text { Parameter } \\
\text { estimate }{ }^{\#}(\mathrm{~mm} \\
\mathrm{Hg})\end{array}$ & $\mathrm{p}$-value & $\begin{array}{c}\text { Parameter } \\
\text { estimate }(\mathrm{mm} \\
\mathrm{Hg})\end{array}$ & $\mathrm{P}$-value \\
\hline $\begin{array}{l}\text { Minimal width } \\
\text { of the kidney } \\
\text { cortex }\end{array}$ & $(\mathrm{mm})$ & -0.6 & 0.07 & -1.5 & 0.005 & -1.1 & 0.002 \\
\hline Kidney length & $(\mathrm{mm})$ & 0.1 & 0.29 & 0.2 & 0.42 & 0.0 & 0.80 \\
\hline \multirow{3}{*}{$\begin{array}{l}\text { Parental history } \\
\text { of BEN }\end{array}$} & Mother & 2.0 & 0.25 & 6.7 & 0.03 & 4.3 & 0.02 \\
\hline & Father & 1.9 & 0.33 & 3.2 & 0.35 & 1.5 & 0.48 \\
\hline & Both & 3.3 & 0.06 & 9.9 & 0.002 & 6.3 & 0.001 \\
\hline
\end{tabular}

\# Adjusted for sex, age, body surface area, diabetes, parental history of hypertension (mother, father, both, none), smoking (current, ex-smoker, never), and lead blood concentration.

years. However, they are likely to have developed precursors of the disease before becoming pregnant, which, however, must be sufficient in themselves to initiate a higher risk in the offspring for having a smaller kidney cortex width and increased systolic and pulse pressure.

Hence, a maternal history of BEN may have both a direct and an indirect effect on blood pressure in offspring. Indirectly, maternal BEN seems to decrease kidney cortex width, which in turn increases blood pressure in adult offspring. Directly, maternal BEN seems to initiate regulations likely to raise the average blood pressure in affected offspring. However, hypertension is not a predominant feature in BEN offspring. Thus, it is unlikely that the reduction in kidney cortex width in BEN offspring results from hypertension.

Renal mass is considered to contribute directly to the development and maintenance of hypertension $[16,19,28]$. Also renal scarring, an index of chronic damage, has also been related to blood pressure [29]. Since we have previously reported a reduced kidney cortex width in BEN offspring [14], our finding that minimal cortex width is related to blood pressure is in agreement with prior reports.

However, in BEN patients, whose kidneys shrink, the lack of increased blood pressure has been considered to be a typical characteristic before the disease reaches its final stage [3-9]. The reason for this unusual association has never been explained. We were surprised to find that BEN offspring had an average increased systolic blood pressure, in particular related to a maternal history of BEN. In agreement with our finding, Arsenovic et al. recently also reported an increased prevalence of hypertension (20 out of 47 persons) in BEN family members [30].

Since our data is based on adult offspring, we are uncertain about the future development of blood pressure in this group. There are three possibilities: (I) Offspring of BEN patients will not develop BEN but maternal BEN may lead to subclinical changes such as an increase in average blood pressure. An argument against this option is that we have found reduced kidney sizes and increased protein excretion in the BEN offspring, which may be considered as early signs of BEN [14]. (II) BEN offspring will develop BEN and their higher average blood pressure will disappear with the progression of BEN. One speculation is that the juxtaglomerular cells become injured and thus the renin-angiotensin system also is impared, which may prevent hypertension. (III) A third option is that the reported lack of hypertension in BEN patients was not based on scientifically sound conclusions and needs to be revised.

\section{Conclusion}

We found that adult offspring of BEN patients have an average increased blood systolic pressure and pulse pressure, determined in two repeated measurement one year apart. This is contrary to reports in BEN patients, who do not have this characteristic. Surprisingly, the increase was related to a maternal history of BEN, or a history of BEN in both parents, but not to a paternal history alone. Increased blood pressure was also associated with a reduction of the minimal width of the kidney cortex, but not with a reduction in kidney length. In our understanding, these findings emphasize the role of maternal priming in determining susceptibility for increased blood pressure. Balkan endemic nephropathy may serve as a model to better understand the development of both kidney disorders and their related blood pressures.

\section{Competing interests}

The author(s) declare that they have no competing interests.

\section{Authors' contributions}

PSD developed and designed the study and helped write the report. SDT assisted in analyzing the data, literature 
review, and writing the discussion. RBG conducted the analyses of lead in blood, and assisted in writing the discussion. VAS conducted the clinical examinations of the study subjects and contributed to the interpretation. AGB conducted the ultrasound examinations of the study subjects and contributed to the interpretation. WJK helped design the study and conducted the statistical analysis and worked on the manuscript. All authors read and approved the final manuscript.

\section{Acknowledgements}

This research was supported by the National Institutes of Health, USA, Research Grant \# ROI TW006192 (Fogarty International Center and the National Institute of Environmental Health Sciences), awarded to the National Center of Public Health Protection, Sofia, Bulgaria.

The authors thank Susan Davis for suggestions on the manuscript.

\section{References}

I. Andersen MJ, Agarwal R: Etiology and management of hypertension in chronic kidney disease. Med Clin North Am 2005, 89(3):525-47.

2. Shoji T, Nishizawa $Y$ : Chronic kidney disease as a metabolic syndrome with malnutrition - need for strict control of risk factors. Intern Med 2005, 44(3): 179-87.

3. Danilovic V, Djurisic M, Mokranjac M, Stojimirovic B, Zivojinovic J, Stojakovic P: Porodicna oboljenia bubrega u selu Sopic izvazvana hronicnom intoksikacijom olovom. Srpski Arh Tcelok Lek 1957, 85(10): III5-II25.

4. Danilovic V, Djurisic M, Mokranjac M, Stojimirovic B, Zivojinovic J, Stojakovic P: Chronic nephritis caused by poisoning with lead via the digestive tract (flour). Presse Med 1957, 65(90):2039-2040.

5. Radosevic Z, Radonic M: Klinicka zapazanja o "endemskoj nefropatiji" u Hrvatskoj. Lij vj 1959, 8 I:445-456.

6. Stojimirovic B, Danilovic V, Durisic M, Bogdanovic M, Radojcic V: Saobstenje o rezultatima sistematakog pregleda stanovnika sela Simicevo (Pomoravlje). Higijena 196I, I 3(4):355-359.

7. Bruckner I, Nicifor E: Endemic nephropathy in Romania. In Endemic (Balkan) Nephropathy Edited by: Stefanovic V. Nis, Inst Nephr Haemod; 1979:1 I-I4.

8. Tanchev $Y$, Dorossiev D: The first clinical description of Balkan endemic nephropathy (1956) and its validity 35 years later. In Mycotoxins, Endemic Nephropathy and Urinary Tract Tumours Edited by: Castenagro M, Plestina R, Dirheimer G, Chernozemsky IN, Bartasch H. Lyon: International Agency for Research on Cancer; | $991: 21-8$

9. Polenakovic M: Balkan Nephropathy. In Oxford Textbook of Clinical Nephrology Edited by: Davison A, Cameron JS, Kerr DN, Ritz E, Winearls Ch. Oxford: Oxford University Press; 1998: 1202-1210.

10. Tanchev Y, Evstatiev Z, Dorossiev D, Pencheva J, Zvetkov G: Studies on the nephritides in the District of Vratza. Savremenna Medicina 1956, 7(9): 14-29.

II. Fortza N, Negoescu M: Nefrita cronica azotemia endo-epidemica. Stud Cercet Med 1961, I:217-22I.

12. Vukelic M, Sostaric B, Belicza M: Pathomorphology of Balkan endemic nephropathy. Food Chem Toxicol 1992, 30(3):193-200.

13. Djukanovic L, Bukvic D, Maric I: Creatininne clearance and kidney size in Balkan endemic nephropathy patients. Clinical Nephrology 2004, 6 I (6):384-386.

14. Dimitrov P, Tsolova S, Georgieva R, Bozhilova D, Simeonov V, Bonev $A$, Karmaus W: Clinical markers in adult offspring of families with and without Balkan Endemic Nephropathy. Kidney Int 2006, 69(4):723-9.

15. Marchand MC, Langley-Evans SC: Intrauterine programming of nephron number: the fetal flaw revisited. J Nephrol 200I, 14(5):327-31.

16. Singh GR, Hoy WE: Kidney volume, blood pressure, and albuminuria: findings in an Australian aboriginal community. Am J Kidney Dis 2004, 43(2):254-9.
17. Mackenzie HS, Lawler EV, Brenner BM: Congenital oligonephropathy: The fetal flaw in essential hypertension? Kidney Int 1996:S30-4.

18. Nyengaard JR, Bendtsen TF: Glomerular number and size in relation to age, kidney weight, and body surface in normal man. Anat Rec 1992, 232(2): 194-201.

19. Zumrutdal AO, Turan C, Cetin F, Adanali S: Relationship between renal size and hypertension in patients with chronic renal failure. Nephron 2002, 90(2): 145-7.

20. Danilovic V: Dijagnoza endemske nefropatije. Radovi $62-X L V I I I$. Od med nauka Akad nauka i umj. BiH, Sarajevo 1973, 17:53-64.

21. WHO: World Health Organization-International Society of Hypertension guidelines for the management of hypertension. 1999 [http://new.euromise.org/mgt/whol 1999/whol 999.html].

22. Tsalev D, Lampugnani L, Georgieva R, Chakarova K: Electrothermal atomic absorption spectrometric determination of cadmium and lead with stabilized phosphate deposited on permanently modified platforms. Talanta 2002, 58(2):33 I-340.

23. Little RC, Miliken G, Stroup W, Wolfinger R: SAS System for mixed models Cary, NC: SAS Institute Inc; 1996.

24. SAS Institute: SAS/STAT Software Cary, NC: SAS Institute Inc; 2000.

25. Vassilevski N, Tsolova G, Dimitrov P: Hypertension level among persons aged 25-64 in CINDI program areas. General Medicine 2006 in press.

26. Raman GV, Clark A, Campbell S, Watkins L, Osmond C: Is blood pressure related to kidney size and shape? Nephrol Dial Transplant 1998, I3(3):728-30.

27. Paivansalo MJ, Merikanto J, Savolainen MJ, Lilja M, Rantala AO, Kauma $H$, Reunanen A, Kesaniemi YA, Suramo I: Effect of hypertension, diabetes and other cardiovascular risk factors on kidney size in middle-aged adults. Clin Nephrol 1998, 50(3):161-8.

28. Ots M, Troy JL, Rennke HG, Mackenzie HS, Brenner BM: Impact of the supplementation of kidney mass on blood pressure and progression of kidney disease. Nephrol Dial Transplant 2004, 19(2):337-4 |

29. Quinkler M, Zehnder D, Eardley KS, Lepenies J, Howie AJ, Hughes SV, Cockwell P, Hewison M, Stewart PM: Increased expression of mineralocorticoid effector mechanisms in kidney biopsies of patients with heavy proteinuria. Circulation 2005, I I 2(10): 1435-43.

30. Arsenovic A, Bukvic D, Trbojevic S, Maric I, Djukanovic L: Detection of renal dysfunctions in family members of patients with balkan endemic nephropathy. Am J Nephrol 2005, 25(I):50-4.

\section{Pre-publication history}

The pre-publication history for this paper can be accessed here:

http://www.biomedcentral.com/1471-2369/7/12/prepub

Publish with Biomed Central and every scientist can read your work free of charge

"BioMed Central will be the most significant development for disseminating the results of biomedical research in our lifetime. "

Sir Paul Nurse, Cancer Research UK

Your research papers will be:

- available free of charge to the entire biomedical community

- peer reviewed and published immediately upon acceptance

- cited in PubMed and archived on PubMed Central

- yours - you keep the copyright

Submit your manuscript here:

http://www.biomedcentral.com/info/publishing_adv.asp
BioMedcentral 